\title{
Protocolo de cuidados de enfermagem no ambiente aeroespacial a pacientes traumatizados: cuidados antes do voo
}

\author{
Protocol of nursing care to traumatized patients in the aerospace environment: care before flight \\ Protocolo de cuidados de enfermería en el ambiente aeroespacial a pacientes traumatizados: \\ cuidados antes del vuelo
}

\section{Gabriela Schweitzer', Eliane Regina Pereira do Nascimento", André Ricardo Moreira"', Kátia Cilene Godinho Bertoncello"}

\begin{abstract}
' Universidade Federal de Santa Catarina, Hospital Universitário Polydoro Ernani de São Thiago; Departamento de Enfermagem, Programa de Pós-Graduação em Enfermagem, Grupo de Estudo no Cuidado de Pessoas nas Situações Agudas de Saúde. Serviço de Atendimento Móvel de Urgência de Santa Catarina, UTI Terrestre e Aérea. Florianópolis-SC, Brasil. "Universidade Federal de Santa Catarina, Departamento de Enfermagem, Programa de Pós-Graduação em Enfermagem, Grupo de Estudo no Cuidado de Pessoas nas Situações Agudas de Saúde. Florianópolis-SC. Brasil.

II' Universidade Federal de Santa Catarina, Departamento de Enfermagem, Programa de Pós-Graduação em Enfermagem

(Mestrando), Grupo de Estudo no Cuidado de Pessoas nas Situações Agudas de Saúde. Serviço de Atendimento Móvel de Urgência de Santa Catarina, UTI Terrestre e Aérea. Florianópolis-SC, Brasil.
\end{abstract}

Submissão: 23-09-2010 Aprovação: 03-02-2012

RESUMO

Teve-se como objetivo apresentar um protocolo de cuidados de enfermagem na pré-remoção aeroespacial de pacientes adultos vítimas de trauma. Trata-se de uma pesquisa qualitativa, convergente assistencial, realizada na Divisão de Operações Aéreas, em São José-SC, entre abril a junho de 2010. Baseou-se nos princípios do Prehospital Trauma Life Support. Utilizou-se de entrevista individual e de encontros em grupo. Participaram os oito enfermeiros do serviço. O protocolo contempla os cuidados relativos à segurança no embarque; desembarque; avaliação da cena; avaliação primária; avaliação secundária e estabilização do paciente. O protocolo propiciará uma prática de cuidado mais segura aos pacientes aerorremovidos.

Descritores: Enfermagem em emergência; Ferimentos e lesões; Resgate aéreo; Medicina aeroespacial; Cuidados de enfermagem.

ABSTRACT
The study aimed to present a protocol for nursing care in pre aerospace removing of adult victims of trauma. A qualitative convergent care research was performed at the Division of Air Operations in the municipality of San Jose-SC, Brazil, from April to June 2010. The study was based on the principles of the Pre-hospital Trauma Life Support. Individual interviews and group meetings were used. Eight nurses participated in the service. The proposed protocol includes safety boarding, disembarking, assessment of the scene, primary assessment, secondary assessment and stabilization of the patient. The protocol will provide a safer nursing practice care to patients aero removed.

Key words: Emergency nursing; Wounds and injuries; Air ambulances; Aerospace medicine; Nursing care.

\section{RESUMEN}

Este estudio tuvo como objetivo presentar un protocolo para la atención de enfermería en la remoción pre aeroespacial de las víctimas adultas de trauma. Se trata de una investigación cualitativa, convergente asistencial, levada a cabo en la División de Operaciones Aéreas, en San José-SC, de abril a junio de 2010. La investigación levó en cuenta los principios del Prehospital Trauma Life Support. Para su elaboración, realizó-se entrevistas individuales y reuniones de grupo. Ocho enfermeras participaron en el estudio. El propuesto protocolo cubre los cuidados relativos a la seguranza durante el embarque y el desembarque; a la evaluación de la escena; a la evaluación primaria; a la evaluación secundaria y la estabilización del paciente. El protocolo servirá a una atención de enfermería más segura para los pacientes aerotransportados.

Palabras clave: Enfermería de urgencia, Heridas y traumatismos, Ambulancias aéreas; Medicina aeroespacial; Atención de enfermería.

Recorte da Dissertação de Mestrado "Protocolo de cuidados de enfermagem no ambiente aeroespacial a adultos vítimas de trauma: uma pesquisa convergente assistencial", apresentada ao Programa de Pós-Graduação em Enfermagem da Universidade Federal de Santa Catarina 


\section{INTRODUÇÃO}

O número de pacientes vítimas de trauma excede os outros tipos de intercorrências clínicas. Em vítimas de trauma, os cuidados pré-hospitalares podem fazer a diferença entre a vida e a morte, entre uma sequela temporária, grave ou permanente ou ainda entre uma vida produtiva e uma destituída de bem-estar ${ }^{(1)}$.

Para uma assistência pré-hospitalar eficiente, é primordial que os profissionais de saúde sejam bem treinados para a rápida identificação das condições do paciente, tenham habilidade no atendimento de vias aéreas, do provável choque e em procedimentos de imobilização. A equipe pré-hospitalar deve assegurar que o paciente seja transportado para um hospital adequado. Às vezes, não só esse hospital pode estar a quilômetros de distância, como um centro de trauma pode ser mais distante ainda ${ }^{(1)}$. Nesse caso, o uso do helicóptero torna-se um importante recurso para manter a vida das vítimas de trauma.

A preocupação com a assistência a essa clientela deu origem ao Prehospital Trauma Life Support - PHTLS ${ }^{(1)}$. O PHTLS visa a aperfeiçoar a avaliação e o tratamento das vítimas de trauma, e tem princípios básicos, como o atendimento aos pacientes segundo a sequência do ABCDE: A (Airway) - atendimento das vias aéreas e controle de coluna cervical; B (Breathing) - respiração; C (Circulation) - circulação; D (Disability) - incapacidade; e E (Expose) - exposição da vítima e proteção do ambiente. Essas letras indicam a prioridade do atendimento e direcionam o profissional de saúde para que não esqueça e/ou cometa erros na assistência ao paciente, contribuindo para um cuidado mais seguro ${ }^{(1)}$. Porém, esse protocolo é específico do ambiente pré-hospitalar e não discute as especificidades da assistência ao paciente aerorremovido.

Os procedimentos de enfermagem, quando acontecem dentro de um helicóptero, encontram situações adversas em relação aos procedimentos realizados num ambiente hospitalar, como: espaço reduzido dentro da aeronave; altitudes que variam de 500 a 5.000 pés ( 1 pé equivale a $0,33 \mathrm{~cm}$ ) em relação ao solo; condições climáticas instáveis e ruídos constantes. Além disso, no ambiente aeroespacial temos os chamados estresses de voo para o usuário aerorremovido: vibração, ruídos, aerodilatação (expansão gasosa nas cavidades corporais devido à queda da pressão atmosférica), alterações de temperatura e umidade. À medida que a altitude aumenta, esses fatores estão mais presentes no interior da aeronave, provocando desconforto ,tanto no paciente quanto na equipe a bordo(2).

O transporte por helicóptero requer uma preparação prévia do paciente, que deverá estar o mais estabilizado possível, pois, dentro da aeronave, devido à limitação do espaço físico interno, a mobilidade do enfermeiro pode ser limitada. A estabilização, como em qualquer atendimento de emergência, deve ser primeiramente dirigida para a via respiratória, depois para a situação hemodinâmica e, por fim, ao estado neurológico ${ }^{(3)}$.

O transporte aéreo do paciente criticamente enfermo somente terá sucesso se for realizada uma criteriosa avaliação da situação, o que incluí o acesso terrestre da aeronave e a estabilização do paciente antes do voo. A equipe deve ser adequadamente preparada para o correto manuseio de todo o material necessário ao atendimento durante o voo. O sistema de comunicação pessoal precisa estar perfeito e, naturalmente, a tripulação de voo deve possuir as qualificações exigidas para operar a aeronave e realizar um transporte seguro para todos ${ }^{(4)}$.

Dessa forma, para contribuir para o preenchimento da lacuna gerada pelo fato de, até o momento, não se ter um protocolo para atendimento a pacientes que serão removidos em helicópteros, justifica-se o desenvolvimento desta pesquisa convergente assistencial, que teve como objetivo o de apresentar um protocolo de cuidados de enfermagem na pré-remoção aeroespacial de pacientes adultos vítimas de trauma.

\section{MÉTODO}

Este é um estudo de abordagem qualitativa que utilizou como método a Pesquisa Convergente Assistencial (PCA), cuja característica principal é manter, durante todo o seu processo, uma estreita relação com a situação da prática assistencial, pois possui a intenção de encontrar soluções para problemas, realizar mudanças e/ou introduzir inovações na assistência ${ }^{(6)}$.

A PCA inclui cinco fases: i) concepção (introdução, justificativa, questão de pesquisa, objetivo, revisão de literatura e referencial); ii) instrumentação (escolha do espaço físico, dos participantes e métodos); iii) perscrutação (estratégias ou instrumentos para obtenção dos dados); iv) análise e interpretação (essa fase permeia todo o processo de desenvolvimento da pesquisa e culmina no item seguinte); v) apresentação do protocolo de cuidados de enfermagem na pré-remoção aeroespacial ${ }^{(6)}$.

O estudo foi realizado na base da Divisão de Operações Aéreas (DOA) do Departamento de Polícia Rodoviária Federal (DPRF), localizada na cidade de São José-SC. Trata-se de uma parceria criada através de um acordo entre o Ministério da Justiça via DPRF e Ministério da Saúde via Secretaria do Estado da Saúde/Serviço de Atendimento Móvel de Urgência (SAMU) do estado de Santa Catarina (SC), em dezembro de 2005. O serviço conta com hangar e um helicóptero, modelo Bell 407, configurado com todos os materiais e equipamentos de suporte avançado de vida, tripulado por um comandante/piloto, um operador de equipamentos especiais, um enfermeiro e um médico.

A pesquisa foi aprovada pelo Comitê de Ética em Pesquisa da UFSC (Processo $n^{\circ}$ 453/2009) e teve o consentimento formal das instituições participantes para a coleta de dados. Os participantes foram informados previamente sobre o objetivo do estudo, assim como acerca das técnicas de coleta adotadas. Todos os oito enfermeiros do DOA concordaram em participar e assinaram o Termo de Consentimento Livre e Esclarecido.

A coleta de dados foi realizada nos meses de abril a junho de 2010 e ocorreu em duas etapas. A primeira constou de entrevista semiestruturada e individual, com os oito enfermeiros, que responderam a seguinte questão norteadora: "Quais cuidados de enfermagem são necessários para apresentar um protocolo assistencial específico para a pré-remoção aeroespacial de pacientes adultos vítimas de trauma?". Com o consentimento prévio dos participantes, todas as entrevistas foram gravadas e, em seguida, transcritas.

Os dados das entrevistas foram analisados de acordo com o conteúdo do ABCDE do PHTLS, observando-se os cuidados 
de enfermagem específicos ao período que antecede o voo de helicóptero.

As entrevistas foram realizadas com o intuito de adquirir informações de cada enfermeiro, a partir da experiência individual adquirida durante o serviço, sobre quais cuidados de enfermagem devem constar no protocolo de cuidados e qual a prioridade dos cuidados e/ou se o profissional tem ou teve alguma dificuldade no atendimento a alguma vítima.

A segunda etapa constou de três encontros em grupo, os quais ocorreram em local, dia e hora combinados com os participantes e tiveram, em média, duração de três horas. As discussões em grupo tiveram a finalidade de socializar as informações obtidas nas entrevistas e, a partir disso, em conjunto com os enfermeiros participantes, desenvolver o protocolo de cuidados fundamentado no conteúdo do PHTLS.

No primeiro encontro foi apresentada e entregue a cada um dos participantes uma folha impressa, com a análise das entrevistas e, assim, discutiu-se o protocolo do ABCDE do PHTLS. Esse momento permitiu aos enfermeiros expressarem suas ideias e opiniões, olharem a situação e identificarem carências ou problemas e discrepâncias, como por exemplo, facilidades ou dificuldades na assistência antes do voo. Continuando os trabalhos, foi iniciada a elaboração dos cuidados de enfermagem, na qual se construiu uma sequência de atendimento ou de cuidados de enfermagem no ambiente aeroespacial baseada nos dados das entrevistas e no PHTLS. Todos os participantes anotavam o que estava sendo produzido na folha entregue no início do encontro.

Nos trinta minutos finais desse encontro, foram divididos entre os enfermeiros, por afinidade, os conteúdos do protocolo: i) orientações de segurança para o voo de helicóptero no embarque e desembarque; ii) avaliação da cena; iii) avaliação primária ( $\mathrm{A}$ - atendimento das vias aéreas e controle da coluna cervical, B - respiração, C - circulação, D - incapacidade, E - exposição e ambiente); iv) avaliação secundária (princípios, exame das fases e outros cuidados). Cada participante teve a tarefa de, na reunião seguinte, trazer a justificativa científica relacionada a cada cuidado de enfermagem referente à etapa ou fase do atendimento que ficou sob sua responsabilidade.

O segundo encontro iniciou com a entrega da relação dos cuidados de enfermagem produzidos na reunião anterior e, em seguida, foi realizada a leitura dos mesmos. Assim, deu-se continuidade à elaboração de mais cuidados, de justificativas e foi aberto um espaço para solucionar dúvidas, fazer ajustes e incluir novos cuidados, com suas respectivas justificativas científicas. Nesse momento, o protocolo começou a ganhar forma.

Por fim, no terceiro e último encontro, os participantes trouxeram as justificativas e a análise de viabilização de cada um dos cuidados de enfermagem que estava a seu encargo, concluindo o protocolo. Primeiramente foi realizada uma leitura em conjunto de todo o protocolo de cuidados. Na medida em que os cuidados e as justificativas eram lidos, ajustes finais iam sendo realizados, bem como a melhora da escrita e da forma. Além disso, foi analisada a viabilidade de cada cuidado e sua justificativa devido aos condicionamentos e limitações que a realidade administrativa do serviço no momento impõe.

\section{O PROTOCOLO DE CUIDADOS DE ENFERMAGEM ANTES DO VOO}

Esse protocolo contempla os cuidados de enfermagem que devem ser realizados ao paciente adulto vítima de trauma no período que antecede o voo. $\mathrm{O}$ material contém as principais orientações de segurança no voo de helicópteros e garante, por meio da avaliação de cena, um ambiente mais seguro para a equipe e os pacientes durante $\mathrm{o}$ atendimento. $\mathrm{O}$ paciente deve ser examinado de maneira que as funções vitais sejam rapidamente analisadas e estabilizadas. Também as condições de risco de morte devem ser identificadas por meio da avaliação sistemática de vias aéreas, ventilação, circulação, incapacidade (estado neurológico) e exposição. Vale ressaltar que, apesar de apresentados em uma sequência linear, os procedimentos podem ser realizados simultaneamente pela equipe.

\section{PROTOCOLO DE CUIDADOS DE ENFERMAGEM ANTES DO VOO*}

\section{ORIENTAÇÕES DE SEGURANÇA PARA O VOO DE HELICÓPTERO NO EMBARQUE E DESEMBARQUE}

Cuidados
Não passar por baixo do corpo, da parte traseira ou da cauda do heli-
cóptero.

Sempre que você se aproximar ou se afastar de um helicóptero, faça-o com o corpo ligeiramente inclinado para frente.

Ao embarcar em um helicóptero ou ao desembarcar dele, sempre o faça pela frente da aeronave, de modo que o piloto possa vê-lo.

Em caso de pouso em terreno inclinado, aproximar-se ou afastar-se da aeronave pelo lado mais baixo do terreno.
Justificativas

O helicóptero possui um rotor de cauda, cujas pás giram num plano vertical e em alta rotação. Esse procedimento evitará que as pás do rotor de cauda ou do rotor principal possam atingi-lo.

Rajadas de vento podem, inesperadamente, mudar a altura das pás e atingi-lo.

O piloto pode, acidentalmente, acionar a aeronave enquanto você estiver passando.

A pá do rotor principal estará mais baixa do lado mais alto do terreno.

* As justificativas deste protocolo foram baseadas nas referências ${ }^{(1-5,7-9)}$. 
Cuidados

Quando se aproximar do helicóptero portando algum objeto (chapéu, capacete, bolsas, papéis, maletas, sacolas, pastas, prancha rígida, maca, soro), segurá-lo na altura da cintura, jamais na vertical ou sobre os ombros. Não tentar apanhar qualquer objeto deslocado pela ação do vento dos rotores.

Desembarcar somente com a solicitação e respectiva autorização do piloto. Depois de autorizado para o desembarque, informar: "livrando fonia". Em caso de operação com os rotores acionados, aguardar autorização para sair e se aproximar da aeronave.

Em caso de cegueira ocasionada por poeira próxima ao helicóptero, parar, sentar e aguardar auxílio do operador de equipamentos especiais.
Justificativas

Dessa forma você evita que qualquer objeto possa "voar" em direção aos rotores, prejudicando o funcionamento do helicóptero. Ao tentar apanhar um objeto, você pode encostar-se ao rotor, ocasionando um grave acidente.

A parte traseira do helicóptero é especialmente perigosa para a equipe em solo porque as pás do rotor normalmente se encontram mais próximas ao solo e são bastante difíceis de serem vistas em rotação.

Esse profissional é o mais treinado em situações como essa.

\section{AVALIAÇÃO DA CENA}

\section{Cuidados}

Conversar com o piloto sobre manter ou não os rotores acionados durante $o$ atendimento à vítima. Se o enfermeiro ou médico perceber que o atendimento vai ser demorado, comunicar ao piloto ou operador, pois pode ser necessário o seu desligamento ou a saída da aeronave do local.

Verificar se está seguro para a equipe atender. Perguntar: o helicóptero está num local que não oferece riscos de acidentes?

O que aconteceu?

Por que foi solicitada ajuda?

Quantas são as pessoas envolvidas?

São necessárias mais unidades para o apoio e para o transporte?
Justificativas

Algumas aeronaves, após o desligamento dos rotores, demoram um tempo para poderem ser acionadas novamente. A operação com rotores acionados acontecem geralmente em atendimentos rápidos ou quando o local do acidente oferece riscos para a equipe.

Os riscos para a segurança de pacientes ou equipe de saúde incluem fogo, fios elétricos caídos, explosivos, materiais perigosos, tráfego de veículos, inundações, armas e condições climáticas/iluminação. Quanto aos riscos de acidentes com a aeronave, a aproximação de pessoas e animais deve ser evitada.

Um histórico completo e preciso do evento traumático bem como uma interpretação adequada dessas informações podem fazer com que o enfermeiro suspeite das prováveis lesões antes de examinar a vítima e indique ou contra indique o uso da aeronave no transporte.

Se a cena envolver mais de um paciente, a situação é classificada como incidente com várias vítimas ou incidente com múltiplas vítimas (desastres). Em situações de desastres, a prioridade muda: em vez de dirigir todos os recursos para o paciente mais grave, deve-se atentar para o salvamento do maior número de vítimas, isto é, fazer o melhor pelo maior número possível (sistema de triagem ${ }^{* *}$ ).

\section{AVALIAÇÃO PRIMÁRIA}

\section{A - ATENDIMENTO DAS VIAS AÉREAS E CONTROLE DA COLUNA CERVICAL}

\section{Cuidados}

Verificar permeabilidade das vias aéreas e controlar coluna cervical com o colar cervical ou manter o pescoço em posição neutra até que o paciente tenha sido totalmente imobilizado.

Realizar desobstrução manual das vias aéreas: rápida inspeção visual da orofaringe.
Justificativas

Assegurar via aérea pérvia é a primeira prioridade no tratamento e reanimação do traumatizado. O controle das vias aéreas necessita de estabilização simultânea da coluna cervical em posição neutra, devido à possibilidade de lesão cervical. As técnicas de controle de vias aéreas devem ser cuidadosamente executadas, pois servirão para manter as mesmas permeáveis e reduzir significativamente o risco de o paciente morrer por asfixia.

Corpos estranhos nas vias aéreas podem ser objetos que estavam na boca do paciente no momento do trauma, como por exemplo: próteses dentárias, goma de mascar, tabaco, dentes e osso. Materiais externos, como vidro de para-brisa quebrado ou qualquer objeto que esteja próximo à boca do paciente no momento do trauma e podem pôr em risco a permeabilidade das vias aéreas. A obstrução também pode ser causada por fratura óssea, colapso de cartilagem ou por trauma de face.

\footnotetext{
** Para não se tornar muito extenso e focar mais na assistência ao paciente adulto traumatizado, neste protocolo não será abordado o sistema de triagem.
} 


\section{Cuidados}

Se obstruídas abrir com:

Métodos manuais: levantamento do queixo no trauma, tração de mandíbula no trauma.

Realizar aspiração, se necessário.

Se ainda obstruídas, abrir com:

Métodos mecânicos: cânulas oro ou nasofaríngeas, máscara laríngea, intubação endotraqueal ou ventilação percutânea.
Justificativas

No paciente inconsciente, a língua fica flácida, caindo para trás e obstruindo a hipofaringe. A língua é a causa mais comum de obstrução das vias aéreas. Usar, então, métodos manuais para remover esse tipo de obstrução, pois qualquer manobra que mova anteriormente a mandíbula afasta a língua da hipofaringe. A manobra de tração da mandíbula no trauma permite abrir as vias aéreas com pouco ou nenhum movimento da cabeça e coluna cervical. A elevação do mento no trauma é utilizada para aliviar uma variedade de obstruções anatômicas das vias aéreas em pacientes que estão respirando espontaneamente. Essas manobras permitem proteger a coluna cervical enquanto se abre a via aérea, afastando a língua da faringe posterior.

A vítima de trauma pode não ser capaz de eliminar de maneira eficiente o acúmulo de secreções, vômito, sangue ou corpos estranhos da traqueia. Nesses casos, a aspiração é importante na manutenção da permeabilidade das vias aéreas.

Utilizar vias aéreas artificiais quando as técnicas manuais falham na correção de obstrução anatômica das vias aéreas. O recurso mais comumente utilizado é a cânula orofaríngea. A máscara laríngea é uma alternativa para controle das vias aéreas em pacientes inconscientes ou com depressão acentuada do nível de consciência. Esse dispositivo proporciona vedação de baixa pressão entre a máscara laríngea e a abertura da glote, sem que haja a inserção direta na laringe. No manejo da via aérea, em situação de emergência, o enfermeiro está autorizado a fazer uso de máscara laríngea (parecer técnico COREN-RS de 08 de Julho de 2009).

\section{B - RESPIRAÇÃO}

\section{Cuidados}

Verificar se está ventilando. Se sim, avaliar frequência ventilatória e esforço inspiratório - elevação do tórax; observar e palpar o tórax rapidamente; auscultar os pulmões para identificar murmúrio vesicular anormal, diminuído ou ausente.

Identificar possíveis lesões: grandes ferimentos com contusão pulmonar podem originar pneumotórax hipertensivo e hemotórax (drenar em solo).

Atentar para turgência de jugular desvio de traqueia e diminuição dos murmúrios vesiculares.

Se estiver ventilando, porém muito lentamente $(\mathrm{FV}<12)$ ou muito rapidamente $(F V>30)$, administrar oxigênio suplementar (reanimador manual e máscara ou máscara com reservatório - ventilação por pressão positiva).
Justificativas

O tórax do paciente deve ser exposto para avaliação da troca ventilatória. As vias aéreas permeáveis não asseguram necessariamente uma ventilação apropriada. A troca de ar adequada deve estar presente além das vias aéreas desobstruídas para prover oxigenação suficiente.

Essas lesões precisam ser vistas na avaliação primária, pois são as que mais frequentemente comprometem a ventilação. Os pacientes com suspeita de ou com pneumotórax definido devem ser diagnosticados e tratados antes da remoção. Um paciente com pneumotórax presente está sujeito a posterior colapso devido à expansão do sequestro de gases. Uma vez colocado o dreno de tórax, o paciente pode ser removido com segurança.

Esses são sinais de um pneumotórax simples e pneumotórax hipertensivo.

Uma frequência ventilatória muito lenta pode indicar isquemia (suprimento deficiente de oxigênio) do cérebro. A condição determinante de frequência ventilatória aumentada é devido ao acúmulo progressivo de $\mathrm{CO}_{2}$ no sangue ou diminuição do nível de $\mathrm{O}_{2}$ sanguíneo. Uma frequência respiratória rápida indica que não há aporte suficiente de oxigênio no tecido. A falta de oxigênio inicia metabolismo anaeróbio e, consequentemente, o aumento de $\mathrm{CO}_{2}$. O sistema de detecção do organismo reconhece o nível elevado de $\mathrm{CO}_{2}$ e alerta o sistema respiratório para aumentar a frequência e exalar esse excesso. Logo, uma frequência aumentada pode indicar que o paciente necessita de melhor perfusão ou oxigenação, ou ambos.

As máscaras escolhidas para dar suporte ventilatório devem ter um ótimo ajuste, estarem equipadas com válvula unidirecional e terem entrada para aporte de oxigênio, proporcionando uma vedação bem adequada e volumes correntes satisfatórios. 


\section{Cuidados}

Se não estiver ventilando: iniciar ventilação assistida e métodos mecânicos.

Se o paciente estiver intubado, encher o cuff com água.

Prender o tubo orotraqueal com dois cadarços.

Colocar oxímetro, verificar a oximetria e ao mesmo tempo a frequência cardíaca.

Quando disponível, utilizar o capnógrafo.
Justificativas

A intubação traqueal é o método preferido para controle das vias aéreas por permitir a ventilação por oxigênio a $100 \%$, eliminar a necessidade de manter a máscara perfeitamente ajustada à face, diminuir significativamente o risco de aspiração, facilitar a aspiração profunda da traqueia, prevenir a insuflação gástrica e permitir uma via adicional de administração de medicamentos. A máscara laríngea é uma alternativa quando não for possível realizar a intubação traqueal, porém ela não evita completamente a regurgitação e nem protege a traqueia. Quando as técnicas anteriores falharem, outros recursos são a ventilação percutânea transtraqueal (traqueostomia por punção) e a cricotireoidostomia cirúrgica, usada como último recurso no atendimento pré-hospitalar em traumas de face e hemorragias traqueobrônquicas persistentes.

Para evitar aumento da pressão interna e consequente isquemia de traqueia quando (o cuff estiver) enchido com ar. Com a altitude, diminui-se a pressão atmosférica e o volume de gás varia inversamente com a pressão, quando a temperatura se mantém constante - Lei de Boyle Mariotte.

Esse cuidado permite uma menor movimentação possível do tubo, evitando lesões na traquéia e a extubação acidental. O ambiente aeroespacial é susceptível as vibrações.

O oxímetro de pulso fornece medidas pontuais da saturação de oxiemoglobina arterial e frequência cardíaca. O objetivo é detectar precocemente o comprometimento pulmonar e deteriorização cardiovascular, antes que os sinais clínicos sejam evidentes. Permite também o reconhecimento e manejo da hipoxemia durante a intubação traqueal de emergência. Movimentação excessiva, umidade no sensor do oxímetro, aplicação e localização inadequada dos sensores e perfusão ruim ou vasoconstrição decorrente de hipotermia são problemas comuns que podem interferir nas medidas.

O capnógrafo mede a pressão parcial de dióxido de carbono em uma amostra de gás. Essa técnica deve ser utilizada para confirmar a posição do tubo traqueal e monitorar continuamente o estado do paciente durante o transporte. Uma queda súbita do $\mathrm{CO}_{2}$ expirado pode ser causada por deslocamento do tubo traqueal ou por diminuição da perfusão e deve induzir uma reavaliação imediata da posição do tubo traqueal e do estado do paciente.

\section{C - CIRCULAÇÃo}

\section{Cuidados}

Checar pulso carotídeo. Se ausente, iniciar compressões torácicas (protocolo de reanimação cardiopulmonar ${ }^{* *}$ ).

\section{Controlar hemorragias.}

Sangramento capilar: escoriações apenas.

Sangramento venoso: camadas mais profundas dos tecidos - realizar compressão direta ou curativo compressivo.

Sangramento arterial: lesão em uma artéria - realizar compressão direta ou curativo compressivo.

O uso de torniquetes é indicado somente em hemorragias muito graves e deve ser aplicado imediatamente próximo ao ferimento hemorrágico, ser suficientemente apertado para bloquear o fluxo arterial e o tempo de uso deve ser até o local do tratamento definitivo.

Não remover objetos embalados.

\section{Justificativas}

Na ausência do pulso carotídeo, o protocolo de RCP deve ser iniciado, pois o paciente está em parada cardíaca.

O rápido controle da perda sanguínea é um dos objetivos principais no atendimento ao traumatizado. Devem-se procurar sangramentos externos significativos e controlá-los tão diretamente quando possível. A hemorragia é a causa mais comum do choque no paciente traumatizado. A compressão direta sobre o local do orifício aumenta a pressão extraluminal e, portanto, reduz a pressão transmural (diferença de pressão dentro do vaso e fora do vaso), ajudando a diminuir o sangramento. Mesmo se a perda sanguínea não for completamente interrompida, ela pode diminuir até o ponto em que o sistema de coagulação do sangue possa parar a hemorragia. Curativos compressivos podem ser utilizados e facilitam o atendimento, pois o profissional fica de mãos livres para outras funções importantes. Com relação ao uso dos torniquetes, embora haja um pequeno risco de uma parte ou todo o membro ser sacrificado, na escolha entre perder um membro ou salvar a vida do paciente, a decisão óbvia é a de preservar a vida.

Esse pode ter lesado vasos importantes, e o próprio objeto pode estar tamponando o sangramento. A remoção do objeto causaria uma hemorragia interna incontrolável. O correto é aplicar uma pressão em apenas um dos lados do objeto.

\footnotetext{
***Neste protocolo, por se tratar apenas do atendimento ao paciente adulto traumatizado no ambiente aeroespacial, não será discutido o protocolo de reanimação cardiopulmonar.
} 


\section{Cuidados}

Observar hemorragias internas: avaliar abdômen e pelve.

Avaliar perfusão:

Checar pulso: avaliar presença, qualidade e a regularidade.

Checar cor da pele e tempo de enchimento capilar.

Checar temperatura relativa da pele e umidade.

Obter dois acessos calibrosos, ou, no mínimo um acesso e de preferência no membro que for mais fácil para o profissional poder acessar dentro da aeronave.

Usar atadura crepe no curativo da punção.

Colocar pressurizador ou bomba de seringa no soro.
Justificativas

Embora o tratamento definitivo da hemorragia interna não seja no ambiente pré-hospitalar, a identificação de uma fonte interna facilitaria o processo de um transporte mais rápido. Traumas fechados e equimoses, traumas penetrantes, distensão ou sensibilidade abdominal, instabilidade pélvica, dor na área pélvica e equimoses perineais são indícios de lesões no abdômen e/ou na pelve e sugerem hemorragia interna.

A avaliação inicial do pulso determina se ele está presente na artéria que se está examinando. O desaparecimento do pulso radial, por exemplo, indica hipovolemia grave ou lesão vascular do braço, particularmente se os pulsos carotídeos ou femorais forem fracos, filiformes e muito acelerados.

A pele pálida ou cianótica tem fluxo sanguíneo inadequado devido a uma vasoconstrição periférica associada à hipovolemia e à interrupção do fluxo sanguíneo para aquela região do organismo, no caso de fraturas.

A capacidade do sistema cardiovascular de encher os capilares, depois que o sangue foi deles "removido" após uma compressão do leito ungueal do hálux ou do polegar, mostra uma medida indireta de perfusão naquela parte do corpo. O aumento do tempo de enchimento capilar indica uma diminuição do débito cardíaco causado por uma hipovolemia. O tempo normal de enchimento capilar não deve ultrapassar dois segundos.

À medida que o organismo desvia sangue da pele para outras partes mais importantes, a temperatura da pele cai. Uma pele fria ao toque indica perfusão cutânea diminuída e decréscimo da produção de energia e, portanto, choque.

Soluções de eletrólitos isotônicas, de preferência aquecidas, como o Ringer Lactato ou salina normal (SF 0,9\%), são utilizadas para reanimação inicial. Esses tipos de fluidos fornecem expansão intravascular transitória e ainda estabilizam o volume vascular, substituindo as perdas de fluidos para os espaços intersticial e intracelular. Um fluido inicial alternativo é a solução salina hipertônica, embora a literatura atual não demonstre qualquer vantagem de sobrevivência. Acessos calibrosos (calibres 14 ou 16) são importantes para uma reposição mais rápida, menos risco de obstrução e de perda durante voo.

Melhor fixação no caso de pele úmida, fria e com sujidades, como sangue ou secreções, evitando perdas acidentais durante o transporte.

As soluções parenterais devem ser colocadas no pressurizador ou em bombas de infusão portáteis com bateria para melhor infundir as soluções, pois eles exercem pressão positiva, evitando assim, o refluxo sanguíneo no cateter e uniformizando o gotejamento da solução. Além disso, o ar no frasco de soro se expande com o aumento da altitude, acelerando o fluxo intravenoso e, com a diminuição da altitude, o fluxo se lentifica porque o volume de ar no frasco de soro diminui. Portanto, devem ser usadas bombas de infusão e pressurizadores para evitar essas alterações no gotejamento do soro.

\section{D - INCAPACIDADE}

\section{Cuidados}

Avaliar nível de consciência com escala de coma de Glasgow: Menor ou igual a 8 - trauma grave.

9 a 12 - trauma moderado.

13 a 15 - trauma mínimo ou sem dano neurológico.
Justificativas

A escala de coma de Glasgow é um método simples e rápido para determinar a função cerebral e é preditivo da sobrevivência do paciente. O enfermeiro pontua o paciente em um escore de acordo com a melhor resposta para cada componente da escala.

Abertura ocular: espontânea (4), sob comando verbal (3), com estímulo doloroso (2) sem abertura ocular (1).

Melhor resposta verbal: adequadas (5), confusas (4), inadequadas (3), sons inteligíveis (2), sem resposta verbal (1).

Melhor resposta motora: obedece aos comandos (6), localiza estímulos dolorosos (5), retirada ao estímulo doloroso (4), responde com flexão anormal aos estímulos dolorosos - decorticação (3), responde com extensão anormal aos estímulos dolorosos - descerebração (2), sem resposta motora (1). 
Cuidados

Atentar para intubação precoce nos casos de traumas moderados.

Avaliar causas ao diminuir o nível de consciência: hipóxia ou hipoperfusão, lesão em sistema nervoso central, intoxicações ou distúrbios metabólicos.

Avaliar pupilas: diâmetro (midriátricas, mióticas, médias), simetria (isocórica, anisocórica) e fotorreação.
Justificativas

O objetivo é manter a proteção da via aérea em casos de rebaixamento do nível de consciência repentinos e/ou hipóxia ocasionada pelo voo. Diferente de uma ambulância, em que se pode parar para atender a vítima, no helicóptero, além disso não acontecer, o espaço reduzido dentro da cabine dificulta a realização dos procedimentos.

Durante o exame, o enfermeiro deve procurar saber se o paciente perdeu a consciência em qualquer momento desde que ocorreu o trauma, quais as substâncias tóxicas que podem estar envolvidas e se o paciente tem algumas condições preexistentes que podem ter produzido a diminuição do nível de consciência, ou o comportamento anormal.

Ao examinar a pupila do paciente, o enfermeiro deve verificar a igualdade da resposta e do tamanho. Uma pequena parcela da população tem pupilas de tamanhos diferentes (anisocoria) como condição normal. Entretanto, mesmo nessa situação, as pupilas devem reagir à luz de modo semelhante. Um escore menor que 14 na escala de coma de Glasgow combinado a um exame pupilar anormal pode indicar a presença de uma lesão cerebral potencialmente fatal.

\section{E - EXPOSIÇÃO E AMBIENTE}

Cuidados

Remover o tanto de roupa necessário para determinar a presença ou a ausência de uma condição ou lesão.

Prevenir a hipotermia, colocar manta térmica e cobertor.

Em caso de queimaduras:

$1^{\circ}$ grau - atingem a epiderme, são avermelhadas e dolorosas.

$2^{\circ}$ grau - atingem a epiderme e partes variadas da derme subjacente, dolorosas e com bolhas. Não estourar no ambiente pré-hospitalar.

$3^{\circ}$ grau - atingem todas as camadas da pele e têm a aparência esbranquiçada, de couro ou carbonizada.

$4^{\circ}$ grau - atingem todas as camadas da pele, tecido adiposo, músculos e ossos e órgãos internos adjacentes.

Estimar a superfície corporal queimada (SCQ) e controlar a reanimação volêmica.

Realizar curativos secos, esterilizados e não aderentes nas lesões por queimaduras. Colocar embaixo e em cima do paciente uma manta térmica. Não utilizar pomadas ou antibióticos tópicos.
Justificativas

A exposição adequada do paciente pela remoção das roupas é necessária para um exame cuidadoso e uma avaliação do paciente por inteiro.

Para cada 1.000 pés de altitude ocorre queda de $2{ }^{\circ} \mathrm{C}$. Sob baixas temperaturas, existe grande dispersão de calor corporal, acarretando hipotermia nos pacientes cujos mecanismos de regulação estejam comprometidos, em especial nos casos de libação alcoólica, idosos, pacientes sob efeito de substâncias anestésicas, intoxicações exógenas e grandes queimados. Nos pacientes vítimas de acidente de mergulho, as roupas molhadas agravam a situação.

O tamanho da queimadura é estimado pela regra dos nove: cabeça $(9 \%)$, tórax e abdômen $(18 \%)$, dorso $(18 \%)$, membros superiores $(9 \%$ cada um), genitália ( $1 \%$ ) e membros inferiores ( $18 \%$ cada um).

Depois de uma queimadura, o paciente perde uma quantidade substancial de líquido intravascular na forma de edema corporal obrigatório, além das perdas por evaporação no local da queimadura. Ao tratar o paciente queimado, o objetivo da reanimação volêmica consiste em calcular e repor os líquidos que se prevê que o paciente irá perder nas primeiras 24 horas após a queimadura. A fórmula de Parkland repõe $4 \mathrm{ml} / \mathrm{kg} / \mathrm{SCQ} \%$. Metade desse líquido deve ser administrada nas primeiras 8 horas depois da lesão e a metade restante nas 16 horas seguintes. As soluções intravenosas mais utilizadas para essa reposição é de Ringer Lactato ou SF 0,9\%.

O curativo seco impede a continuação da contaminação ambiental ao mesmo tempo em que evita que o paciente sinta dor por causa do fluxo de ar sobre as terminações expostas. Pomadas ou antibióticos tópicos não devem ser utilizados, pois impedem a inspeção direta da queimadura na chegada ao hospital. 


\section{AVALIAÇÃO SECUNDÁRIA}

\section{PRINCÍPIOS}

\section{Cuidados}

Ver

Examinar a pele e cada região;

Estar atento para hemorragia externa ou sinais de hemorragia interna, como tensão exagerada em uma extremidade ou hematoma expansivo; Observar presença de lesões, como: escoriações, queimaduras, contusões, hematomas, lacerações e ferimentos penetrantes;

Observar massas, inchaços ou deformidade de ossos.

Ouvir

Observar se há algum som incomum enquanto o paciente inspira e expira;

Observar se há algum som anormal na ausculta do tórax;

Verificar se o murmúrio vesicular é igual e normal em ambos os pulmões;

Sentir

Mover cuidadosamente cada osso na região. Observar se isso produz crepitação, dor ou movimento incomum.

Palpar com firmeza todas as partes do corpo.

\section{Justificativas}

O exame secundário é a avaliação do paciente da cabeça aos pés. Seu objetivo é identificar lesões ou problemas que ameaçam a vida a curto e longo prazo, mas que não foram identificados no exame primário, que é imediato. A abordagem "ver, ouvir e sentir" é usada para avaliar a pele e tudo que ela contém, começando pela cabeça e prosseguindo pelo pescoço, tórax e abdômen até as extremidades, concluindo-se com exame detalhado.

\section{EXAME DAS PARTES}

\section{Cuidados}

Cabeça: palpar todo o couro cabeludo na busca de lesão em partes moles; checar pupilas quanto à reação à luz, ao tamanho, à igualdade, à acomodação ou ao formato irregular; palpar cuidadosamente os ossos da face e crânio para identificar crepitação, desvios, depressão ou mobilidade anormal; atentar para sinal de battle, "olhos de guaxinim" e drenagem de sangue ou líquido céfaloraquidiano (LCR) pelos ouvidos ou nariz; observar sinais de aumento da pressão intracraniana (PIC): diminuição de dois ou mais pontos na escala de coma de Glasgow, pupilas com reação lenta e não reativa, hemiplegia ou hemiparesia ou tríade de Cushing (aumento acentuado da pressão arterial com bradicardia).

Pescoço: identificar contusões, abrasões, lacerações e deformidades, palpar com cuidado, manter em posição neutra e identificar possíveis enfisemas subcutâneos de origem traqueal, pulmonar ou laríngea; observar ausência de dor na coluna cervical.

Tórax: identificar deformidades, áreas de movimento paradoxal, contusões, abrasões, posições de defesa contra a dor, excursão torácica bilateral desigual e saliência ou retração intercostal, supraesternal ou supraclavicular; realizar ausculta pulmonar, reconhecer murmúrios vesiculares diminuídos ou ausentes e que não foram reconhecidos no exame primário; auscultar bulhas cardíacas, se possível.

Abdômen: observar abrasões, equimoses e contusões características de cinto de segurança; palpar cada quadrante para verificar dor, posição de defesa do músculo abdominal ou massas.

Em caso de eviscerações, não colocar o órgão de volta para a cavidade abdominal, deixar as vísceras como estão e protegê-las com compressas estéreis umedecidas com solução salina estéril.
Justificativas

O exame visual da cabeça e da face revelará contusões, abrasões, lacerações, assimetria óssea, hemorragia, defeitos ósseos da face e da caixa craniana e anormalidades do olho, das pálpebras, do ouvido externo, da boca e mandíbula. O sinal de battle refere-se a uma equimose no processo mastóide e os "olhos de guaxinim" relacionam-se a uma equimose periorbital, mas ambas são indicativas de fratura em base de crânio. A saída de fluido claro pelo nariz ou pelo ouvido pode ser LCR e esse fato é sugestivo de lesão cerebral. Quando colocado em gaze, o LCR pode separar-se do sangue, produzindo um "halo" amarelado característico.

Sinais de aumento da PIC indicam hematomas, herniações cerebrais, isquemia e edema cerebral.

Crepitação da laringe, rouquidão e enfisema subcutâneo indicam fratura de laringe. A ausência de dor na coluna cervical pode ajudar a descartar fraturas cervicais. Já a presença de dor pode ajudar a identificar fraturas, luxação ou lesão ligamentar.

A avaliação visual do tórax identifica possíveis lesões. Um ferimento perfurante perto do esterno, por exemplo, pode indicar tamponamento cardíaco. Neste caso, na ausculta, as bulhas estarão abafadas. A contusão sobre o esterno pode ser uma indicação de contusão miocárdica. Murmúrios vesiculares diminuídos indicam possível pneumotórax simples, hipertensivo ou pneumotórax.

Uma observação cuidadosa e avaliação contínua do abdome são importantes nos casos de trauma fechado de órgãos intra-abdominais. Pode haver rompimento de fígado e baço, com grandes perdas sanguíneas.

A maior parte dos órgãos abdominais necessita de um ambiente úmido. Se o intestino ou algum dos outros órgãos abdominais ficarem secos pode ocorrer morte celular. 
Cuidados

Gestantes: no caso da grávida traumatizada, a melhor forma de assegurar a sobrevivência do feto é cuidar bem da mãe. Avaliar a gestante da mesma forma que qualquer traumatizado, porém prestando atenção nas alterações anatômicas e fisiológicas que a gravidez causa nos sistemas do organismo.

Observar, se possível antes do voo, a movimentação fetal.

Pelve: procurar abrasões, contusões, lacerações, fraturas expostas e sinais de distensão; palpar a pelve e procurar instabilidade somente uma vez e pelo profissional mais capacitado da equipe; fazer uma pressão suave anteroposterior da sínfise púbica e, então, pressão medial nas cristas ilíacas bilateralmente, avaliando-se dor e movimentos anormais.

Dorso: realizar o exame do dorso quando o paciente é lateralizado para o rolamento na prancha longa; palpar a coluna para identificar sensibilidade e deformidades.

Extremidades: cada osso e articulação individuais devem ser avaliados por exame visual a procura de deformidade, hematomas ou equimose e por palpação para determinar se há crepitação, dor, sensibilidade ou movimento incomum; verificar a circulação e função dos nervos motores e sensitivos na parte distal de cada extremidade.
Justificativas

No que se refere às alterações anatômicas, além da protuberância óbvia acentuada no final da gravidez, os órgãos abdominais, à exceção do útero, permanecem inalterados. O intestino, que é deslocado um pouco para cima, fica protegido pelo útero nos dois últimos trimestres da gestação. Sobre as questões fisiológicas, ocorre um aumento da frequência cardíaca de 15 a 20 batimentos por minuto acima do normal no $3^{\circ}$ trimestre, dificultando a avaliação da taquicardia. As pressões arteriais sistólica e diastólica caem 5 a $15 \mathrm{mmHg}$ durante o $2^{\circ}$ trimestre, mas voltam ao normal no final da gravidez. Pela $10^{\text {a }}$ semana, o débito cardíaco está aumentado de 1 a 1,5 litros por minuto. Até o término da gestação, pode ocorrer perda de 30 a 35\% do volume sanguíneo materno, sem que apareçam sinais ou sintomas de hipovolemia. O útero gravídico e a placenta são muito vascularizados, o que pode provocar hemorragia intensa.

O feto normal, ao nível do mar, tem uma pressão parcial de $\mathrm{O}_{2}$ arterial $\left(\mathrm{PAO}_{2}\right)$ de $32 \mathrm{mmHg}$ no sangue do cordão umbilical e $10,6 \mathrm{mmHg}$ de pressão parcial de $\mathrm{O}_{2}$ venoso $\left(\mathrm{PVO}_{2}\right)$ no cordão. Esse é um grande contraste para a mãe com $\mathrm{PAO}_{2}$ de $100 \mathrm{mmHg}$ e $\mathrm{PVO}_{2}$ de $40 \mathrm{mmHg}$. Se a mãe está respirando a 8.000 pés de altitude, sua $\mathrm{PAO}_{2}$ cai para $64 \mathrm{mmHg}$, mas a $\mathrm{PAO}_{2}$ fetal cai somente para $25,6 \mathrm{mmHg}$. Mesmo a esse nível, a saturação de oxigênio da hemoglobina materna será ainda de aproximadamente de $90 \%$. Além disso, no que tange à circulação fetal quanto à liberação de oxigênio, em hipóxia moderada, a curva de dissociação da hemoglobina fetal difere da materna, sendo mais efetiva a fetal. Portanto, o feto é mais resistente à hipóxia de voo. Porém isso muda com relação a perdas sanguíneas. O feto pode estar em sofrimento mesmo que as condições maternas e sinais vitais da mãe pareçam estáveis. Isso acontece porque o corpo desvia o sangue do útero (e do feto) para os órgãos vitais. As alterações neurológicas da mãe deverão ser observadas, embora a etiologia exata não possa ser identificada no ambiente pré-hospitalar.

Fraturas pélvicas podem produzir hemorragia interna maciça, resultando em deteriorização rápida da condição do paciente. A pelve só deve ser palpada uma vez devido ao risco de agravamento de uma possível hemorragia.

Evitar a movimentação excessiva do traumatizado.

As lesões de extremidades resultam em dois problemas primários: hemorragias e instabilidade (fraturas e luxações).

\section{OUTROS CUIDADOS}

\section{Cuidados}

Verificar sinais vitais: pressão arterial e temperatura.

\section{Histórico SAMPLA:}

Sinais e sintomas.

Alergias: principalmente a medicamentos.

Medicações que o paciente faz uso.

Passado médico e antecedentes cirúrgicos.

Líquidos e alimentos: risco para vômitos e aspiração, em caso do paciente necessitar de cirurgia após o trauma.

Ambiente: eventos que levaram ao trauma.

Reavaliar a função neurológica mais detalhadamente que na avaliação primária; incluir avaliação da função motora e sensitiva e a observação da resposta pupilar.

\section{Justificativas}

Reavaliar constantemente o paciente, pois mudanças significativas do seu estado de saúde podem ocorrer. A verificação da pressão arterial pode ser feita manualmente.

Serve como lembrança para um rápido histórico de saúde do paciente e que deve ser repassado à equipe de saúde no hospital.

Observar se houve alterações ou piora no estado de saúde do paciente. 


\section{CONCLUSÃO}

O método utilizado nesta investigação propiciou aos enfermeiros a oportunidade de repensar a prática do cuidado. $\mathrm{O}$ protocolo apresentado possibilitará aos enfermeiros sistematizar a assistência, orientando as ações necessárias para o cuidado. Além disso, poderá servir para dar visibilidade ao papel do enfermeiro de bordo no trato ao paciente traumatizado.

O modo como foi estruturado o protocolo deverá facilitar o seu uso pelo enfermeiro em cada plantão, devido a sua praticidade em determinar a conduta a ser seguida com segurança.

A transferência dos resultados não é a de generalizações e sim de socialização. Todavia, nada impede que esse protocolo possa ser transferido para outros cenários/contextos semelhantes. Lembrando que esse instrumento de cuidados de enfermagem aplica-se apenas para pacientes com trauma e para o atendimento que antecede o voo diurno, pois o helicóptero desse serviço não realiza voos noturnos que, por sua vez, exigem uma tecnologia diferenciada. Além disso, uma limitação desse estudo é não contemplar os importantes cuidados que precisam ser aplicados durante e após o transporte aéreo.

Espera-se também que a experiência vivenciada nesse estudo pelos enfermeiros de bordo sirva como estímulo para a realização de novas pesquisas no sentido de modificar, aprimorar e de instrumentalizar a enfermagem aeroespacial, não só a pacientes traumatizados, mas aqueles com outros agravos de saúde.

\section{REFERÊNCIAS}

1. PHTLS: Atendimento pré-hospitalar ao traumatizado. $6^{\mathrm{a}}$ ed. Rio de Janeiro: Elsevier; 2007. 596 p.

2. Reis MCF, Vasconcellos DRL, Saiki J, Gentil RC. Os efeitos da fisiologia aérea na assistência de enfermagem ao paciente aerorremovido e na tripulação aeromédica. Acta Paul Enferm. 2000; 13(2):16-25.

3. Oliva R. Valoración inicial del paciente com trauma grave. In: Moraza AS, Ayuso DF. Manual de helitransporte sanitario. Barcelona: Elsevier; 2008. p. 203-9.

4. Mannarino L, Timerman S. Transporte terrestre e aéreo do paciente crítico. Rev Soc Cardiol Estado de São Paulo. 1998; 8(4):866-78.

5. Trentini M, Paim L. Pesquisa convergente-assistencial: um desenho que une o fazer e o pensar na prática assistencial em saúde-enfermagem. $2^{\mathrm{a}}$ ed. Florianópolis: Insular; 2004. 143 p.

6. Temporal W. Medicina aeroespacial. Rio de Janeiro: Luzes; 2005. 471 p.

7. Batista SA. Transporte aeromédico. In: Sousa RMC, Calil AM, Paranhos WY, Malvestio MA. Atuação no trauma: uma abordagem para a enfermagem. São Paulo: Atheneu; 2009. p.493-507.

8. Thomaz RR, Miranda MFB, Souza GAG, Gentil RC. Enfermeiro de bordo: uma profissão no ar. Acta Paul Enferm. 1999; 12(1): 86-96.

9. Chapleau W. Manual de emergências: um guia para primeiros socorros. Rio de Janeiro: Elsevier; 2008. 408 p. 